\title{
Fluxos de capitais e taxa de câmbio no Brasil: uma aplicação do modelo de vetores auto-regressivos (VAR)
}

\author{
Larissa Naves Deus \\ Mestranda em Economia pela Universidade Federal de Uberlândia (PPGE/IE - UFU). \\ Endereço para contato: Rua Arlindo Teixeira, 613 - Bairro Martins - Uberlândia - MG \\ CEP: 38400-352 - E-mail: larissand6@hotmail.com
}

Recebido em 13 de novembro de 2014. Aceito em 16 de janeiro de 2015.

\begin{abstract}
Resumo
Este trabalho analisa as relações existentes entre os fluxos de capitais que ingressam no Brasil e a taxa de câmbio real deste país, expressa em R\$/U\$. Especificamente, busca-se investigar as influências que os fluxos financeiros, registrados nas sub-contas da Conta Financeira do Balanço de Pagamentos brasileiro, exercem no comportamento da taxa de câmbio real, além de se verificar, também, as influências do comportamento desta taxa sobre a atração de capitais externos. Para tanto, utiliza-se o modelo de vetores auto-regressivos (VAR), Funções de Resposta aos Impulsos e Análise de Decomposição de Variância. As evidências obtidas sugerem que o comportamento da taxa de câmbio brasileira é fortemente influenciado pela entrada de fluxos financeiros no país. Destaca-se, ainda, que os fluxos de mais curto prazo, de modo geral com perfil especulativo, apresentam significativo peso no comportamento do câmbio, o que se estende para a volatilidade desta taxa e, consequentemente, para a instabilidade macroeconômica a que o país está sujeito ao depender fortemente destes fluxos.
\end{abstract}

Palavras-chave: Fluxos de capitais. Taxa de câmbio real. Vetores auto-regressivos.

\begin{abstract}
This paper examines the relationship between capital flows entering the Brazil and the real exchange rate in this country, expressed in $\mathrm{R} \$ / \mathrm{U} \$$. Specifically, we seek to investigate the influences that financial flows, sub-accounts registered in the Financial Account of the Brazilian Balance Payments exert on the behavior of the real exchange rate, and also to check the influences of the behavior of charge on the attraction external capital. We also use the vector autoregressive model (VAR), the Impulse Response Functions and Variance Decomposition Analysis. The evidence suggests that the behavior of the Brazilian exchange rate is heavily influenced by the inflow of financial flows in the country. Note also that the flows of short-term, generally with speculative profile, have significant bearing on the behavior of exchange rates, which extends to the volatility of this rate and hence to macroeconomic instability that the country is subject to rely heavily on these flows.
\end{abstract}

Key-words: Capital flows. Real exchange rate. Vector autoregression.

Econ. e Desenv., Santa Maria, vol. 26, n.2, p. 85 - 106, jul. - dez. 2014 


\section{INTRODUÇÃO}

O estudo da inserção internacional de um país pode ter como foco o âmbito comercial ou o âmbito financeiro, sendo a taxa de câmbio a variável chave para se analisar ambas as esferas. Na última década essa taxa tem apresentado uma tendência de apreciação no Brasil, o que leva alguns autores a argumentarem quanto aos impactos de longo prazo na estrutura produtiva do país, além da ameaça provocada pelos fluxos correntes de capitais nessa economia, tendo em vista a constante alteração no volume e direção desses capitais internacionais e seus impactos sobre a expansão e retração dos influxos financeiros para as economias emergentes.

Um primeiro eixo de discussão busca entender a expressiva valorização da moeda brasileira através do desempenho das exportações, além da composição da pauta exportadora, o que nos remete a estudos referentes à desindustrialização e à Doença Holandesa ${ }^{1}$ no país. Já num segundo eixo se encontra a análise do locus financeiro da economia, em que se observa que, mesmo com a redução da taxa de juros de $25 \%$ em janeiro de 2003 para $10 \%$ em dezembro de 2013, o diferencial de juros interno e externo ainda é muito significativo. Isso favorece a entrada exacerbada de capitais na economia brasileira, sendo que, devido a esse diferencial, o perfil de tais fluxos é predominantemente especulativo. Vale ressaltar que, como numa relação que se auto-reforça, a forte entrada de recursos externos pode influenciar a apreciação da taxa de câmbio real, causando efeitos em toda a dinâmica econômica do país.

É com base nesse segundo eixo de discussão que esse trabalho se desenvolve. Buscase analisar as relações e influências existentes entre o comportamento da taxa de câmbio brasileira e os influxos de capitais no país. Especificamente, o trabalho parte da ideia de que a entrada significativa de recursos externos é capaz de influenciar o comportamento da taxa de câmbio do país, assim como essa taxa exerce influências na atração dos influxos de capital.

Assim, o trabalho se apóia na literatura que trata dos fluxos de capitais destinados a economias emergentes, como a brasileira. Tais países possuem a peculiaridade de atraírem capitais por razões que não apenas ligadas às suas condições internas. Pelo contrário, a conjuntura externa somada às políticas dos países centrais e o diferencial de juros oferecido pelos países emergentes condicionam a atratividade dos capitais externos a essas economias, de forma que a dimensão imediata dessa condição diz respeito à vulnerabilidade a que esses países estão expostos, ao dependerem de capitais que se guiam pela oportunidade de ganhos excessivos em prazo curto, o que os caracterizam como especulativos. Com isso, a qualquer reversão de expectativas, esses capitais migram das economias emergentes para as economias desenvolvidas, que lhes oferecem maior segurança ${ }^{2}$.

\footnotetext{
1 A desindustrialização pode ser relacionada ao declínio sustentado tanto da participação da manufatura no emprego total como da participação da manufatura no PIB. A desindustrialização decorrente da apreciação da taxa real de câmbio devido à especialização em recursos naturais da pauta exportadora é também conhecida como Doença Holandesa.

2 Tal condição se deve, sobretudo, às assimetrias financeiras e monetárias existentes no Sistema Financeiro e Monetário Internacional (SFMI), em que se concebe a hierarquia das moedas, a dimensão e os determinantes que guiam os fluxos financeiros para países desenvolvidos ou emergentes. De maneira geral, a hierarquia das moedas faz referência à existência de 3 tipos de moeda no SFMI, a moeda-chave, as conversíveis e as não conversíveis, sendo que a conversibilidade se dá pelo poder de exercer as três funções típicas da moeda em âmbito internacional. Ademais, a dimensão dos fluxos se mostra pouco significativos nos países emergentes quando comparados aos países desenvolvidos (detentores da moeda-chave e conversíveis), além do fato de que os
} 
Além da análise teórica feita por meio da literatura que trata dos fluxos financeiros e suas relações com a taxa de câmbio, esse trabalho se utiliza do método de vetores autoregressivos (VAR) para captar tais influências, com o apoio das Funções de Resposta aos Impulsos e a Análise de Decomposição de Variância. Logo, além dessa introdução e das considerações finais o trabalho conta com três seções. Na primeira faz-se a análise do referencial teórico, na segunda apresenta-se a metodologia VAR, assim como o tratamento dos dados, enquanto a terceira seção busca analisar os resultados do modelo.

\section{Fluxos de capitais e taxa de câmbio}

\subsection{O debate acerca da liberalização financeira}

Diante da tendência de apreciação que a taxa de câmbio brasileira vem apresentando nos últimos anos, somada aos efeitos desencadeados pela crise financeira de 2008, a preocupação com a instabilidade externa a que países que dependem fortemente dos movimentos de capitais, ditados pelos ciclos de liquidez internacional, para gerirem seu balanço de pagamentos voltou à tona.

Pode-se considerar que foi a partir da década de 1980 que o processo de liberalização financeira se intensificou, partindo dos países desenvolvidos e se estendendo também aos países emergentes. Esse processo encontra apoio e justificativa nos argumentos, do denominado mainstream economics, referentes à hipótese de estabilidade e eficiência dos mercados financeiros.

De modo geral, essa hipótese aponta que com a abertura financeira há a diversificação dos riscos entre os agentes, no caso, os países; acesso facilitado destes à poupança externa; facilidade em financiar desequilíbrios no balanço de pagamentos; o que leva, como objetivo último, a maiores níveis de crescimento econômico. Damasceno (2007) sintetiza os argumentos favoráveis à integração financeira internacional ${ }^{3}$, em que todos os canais elencados a seguir levam à eficiência na alocação de recursos e ao crescimento de longo prazo dos países. Os canais por onde a integração financeira internacional age para atingir tais objetivos correspondem ao aumento da poupança doméstica, à redução dos custos de capital, à transferência de tecnologia, ao desenvolvimento do sistema financeiro doméstico e à disciplina macroeconômica.

Já os estudiosos contrários, ou melhor, críticos à liberalização financeira apontam que há certa fragilidade nos argumentos que justificam esse processo e negam a hipótese de mercados eficientes. A justificativa para essa negação se baseia na ideia de que há imperfeições nos mercados financeiros, decorrentes tanto de assimetrias de informação entre um agente e outro, quanto da crença na incerteza fundamental que está inerente nas decisões econômicas e não econômicas dos agentes, no sentido de que:

determinantes dos fluxos a economias emergentes são majoritariamente exógenos às condições internas dessas economias (CARNEIRO, 1999).

${ }^{3}$ Os termos liberalização financeira e integração financeira são abordados na literatura como tendo o mesmo sentido, referente à integração de um mercado nacional ao mercado financeiro global.

Econ. e Desenv., Santa Maria, vol. 26, n.2, p. 85 - 106, jul. - dez. 2014 
A racionalidade subjacente à decisão dos agentes num contexto caracterizado por instabilidade financeira estrutural, incerteza, assimetria de informação e de poder e opiniões divergentes é bastante diferente daquela postulada pela teoria das expectativas racionais. Não existe nesse contexto o homo economicus otimizador num universo estacionário definido por leis econômicas conhecidas por todos. (...) Em suma, ao contrário do suposto pela teoria dos mercados eficientes, as informações relevantes sobre os fundamentals da economia não estão disponíveis, de forma homogênea, para todos os participantes do mercado. O comportamento dos investidores num ambiente de incerteza e informações incompletas é condicionado, como mostrou Keynes (1936), pela busca de ganhos de curto prazo e pela adoção de convenções, que resultam em ações uniformes e efeitos de "manada". (PRATES, 1999, p. 66).

Carvalho e Sicsú (2006) apontam que para ser válida a hipótese da eficiência dos mercados, principal argumento a favor da liberalização financeira, é preciso que diversos pressupostos sejam respeitados. Estes pressupostos são os necessários para determinar não só a existência de equilíbrios competitivos como também mecanismos que garantam a convergência das operações de mercado para esse equilíbrio. As imperfeições existentes que travam a existência natural desse equilíbrio são referentes aos mercados incompletos e às assimetrias de informação entre os agentes. Quanto à incompletude dos mercados, que inclui as externalidades a que esses estão expostos, os autores afirmam que "exceto se as expectativas forem racionais (...), a incompletude dos mercados fatalmente levará a previsões incorretas de preços futuros e a decisões ineficientes" (CARVALHO e SICSÚ, 2006, p. 13). Em relação à assimetria de informações os autores denotam que esta também reduz a eficiência do sistema de preços na obtenção da alocação ótima de recursos, contrariando a validade da hipótese da eficiência dos mercados.

Além da visão crítica à hipótese de eficiência dos mercados existem autores que se opõem à liberalização financeira a partir da consideração de que há uma incerteza fundamental que cerca todas as decisões dos agentes, ideia herdada dos ensinamentos de Keynes (1985). Tomando o futuro como incerto, os agentes são guiados a partir de expectativas futuras, baseadas em fatos passados, que não tem uma probabilidade exata de acerto. Assim, "nesta abordagem, uma economia de mercado é marcada pela dependência de trajetória (path dependency) e não há mecanismos que a façam convergir para uma posição predeterminada (...) ações são orientadas por expectativas que apenas em parte são influenciadas por dados objetivos" (CARVALHO e SICSÚ, 2006, p. 15).

Vale ressaltar que as operações realizadas nos mercados financeiros estão ainda mais expostas à incerteza fundamental, uma vez que as negociações se fazem, na maioria das vezes, através de recompensas futuras e, dado que o futuro é incerto, essas negociações estão sujeitas a diversos condicionantes, como por exemplo, o estado de confiança dos agentes, ao comportamento de variáveis macroeconômicas das economias envolvidas na negociação, dentre outras. Assim,

Nessa visão, mercados não podem ser eficientes para revelar uma realidade subjacente. Mercados podem ser eficientes para coordenar comportamentos, mas para tanto devem estar apoiados em regras e instituições que promovam a coordenação e canalizem as expectativas, limitando as possibilidades que o futuro abre de modo a diminuir a dispersão das expectativas. Nem sempre isso é possível, e controles e regulações têm de ser definidos para reforçar a coerência dessa economia. A incoerência e a crise são possibilidades sempre presentes e a 
intervenção extramercado se faz necessária para conter as tendências imanentes à desagregação intrínsecas a economias de mercado e a mercados financeiros, em particular. (CARVALHO e SICSÚ, 2006, p. 15).

No trecho acima os autores fazem referência à possibilidade de ocorrência de crises. A partir dos anos 1970 tanto os países desenvolvidos quanto os países em desenvolvimento foram protagonistas de grandes crises financeiras, que se alastraram rapidamente de um país a outro, sendo características do novo momento vivido pelas economias de mercado, que passam a terem seus mercados integrados internacionalmente.

O documento da Cepal (2002) enfatiza que essas crises financeiras são resultado da volatilidade característica dos mercados financeiros apresentada nas últimas décadas, que se explica principalmente pela falta de informações sobre o futuro, tida pelo documento como a falha de mercado fundamental. Os meios pelos quais essa volatilidade dos mercados pode ser acentuada se relacionam à insuficiente regulação característica do processo de liberalização, ao efeito contágio provocado pelas restrições de liquidez enfrentadas pelos investidores institucionais e ao uso por vários agentes do mesmo sistema de avaliação de riscos, que tende a acentuar o efeito contágio.

Levando em consideração a ideia de que os mercados financeiros contemporâneos convivem com certa instabilidade e volatilidade financeiras, Plihon (1995) aborda a predominância da lógica especulativa nas relações financeiras a partir da terceira fase da globalização. $\mathrm{O}$ autor denota que com o crescimento das finanças internacionais, possibilitado pela abertura e desregulamentação financeira dos países, a própria natureza do sistema econômico passou a ser dominado pela especulação, sendo que as características do predomínio da especulação nas relações econômicas podem ser resumidas em quatro atributos. Em primeiro lugar, as operações especulativas envolvem uma tomada de riscos, que podem ser exemplificadas pelas posições tomadas em taxa de juros ou câmbio. Em segundo lugar, tais operações são motivadas pela expectativa de ganhos futuros, relacionada à variação antecipada dos preços dos ativos. Em terceiro lugar, essas operações não têm contrapartida no lado real da economia, são, dessa forma, independentes. E, por fim, as operações especulativas são, quase sempre, realizadas a prazo, ou seja, os capitais envolvidos nas operações são emprestados aos especuladores.

Indo ao encontro do argumento de Plihon (1995), Minsky (1986) desenvolve mais profundamente a ideia de instabilidade e fragilidade financeira das economias contemporâneas, enfatizando em sua obra a 'mania de desregulamentação' nas décadas de 1970 e 1980, sendo a instabilidade financeira consequência das necessidades financeiras de economias industriais e das em processo de industrialização. A associação entre as necessidades financeiras das economias e a mania de desregulamentação faz com que os agentes econômicos se utilizem cada vez mais dos instrumentos financeiros modernos que tentam preservar os ativos monetários contra o risco a que estão expostos.

Deste modo, tanto para Plihon (1995) quanto para Minsky (1986), a fragilidade financeira a que estão sujeitas as economias contemporâneas é consequência direta do processo de liberalização e desregulamentação financeira. A liberdade dos fluxos de capitais ao migrarem de um país a outro, sem alguma regulação, a fim de buscarem retornos maiores, tornam as economias mais instáveis, já que da mesma forma que esses fluxos se direcionam a

Econ. e Desenv., Santa Maria, vol. 26, n.2, p. 85 - 106, jul. - dez. 2014 
um país antevendo bons retornos, podem desviar-se deste destino, caso as expectativas de retorno sejam revistas.

Vale ressaltar que grande parte dos autores críticos ao processo de liberalização financeira considera que países emergentes sentem mais intensamente os efeitos da fragilidade e instabilidade financeiras. Plihon (1995) aponta que "a chegada maciça de capitais privados nos MFE [Mercados Financeiros Emergentes], favorável a priori ao crescimento dos países receptores, pode provocar a gestação de bolhas especulativas" (p. 71). Isto porque, com a entrada maciça de capitais há a ilusão de êxito financeiro por parte dos agentes dessa economia, o que leva à valorização da moeda local. Com isso, há um entrave ao crescimento econômico. Além disso, todas as transações dependem de um conjunto de expectativas dos agentes e, caso haja reversão das expectativas que direcionaram os capitais a essa economia, pode haver grande reversão desses fluxos. Logo, instaura-se um movimento de descrédito por parte dos investidores e a economia passa a funcionar como se estivesse num ciclo vicioso, onde a especulação funciona como motor desse processo. Assim, "é a instabilidade das relações monetárias e financeiras internacionais que gera a vulnerabilidade externa nos países periféricos, incluindo o Brasil" (MUNHOZ e CORRÊA, 2009, p. 9).

Visto assim, a seguir discute-se com mais precisão as características dos fluxos financeiros direcionados às economias emergentes, particularmente no tocante ao Brasil, além de suas influências e relações com as variáveis macroeconômicas, sendo a taxa de câmbio a principal referência neste contexto.

\subsection{Fluxos de capitais e instabilidade macroeconômica}

A análise do perfil dos fluxos financeiros de um país demanda o exame de suas contas externas, que se referem aos fluxos transacionados, registrados no balanço de pagamentos, e aos estoques de ativos e passivos financeiros, representado pela Posição Internacional de Investimento (PII) ${ }^{4}$.

Tabela 1: Inserção Externa do Brasil em termos da Posição Internacional de Investimentos e do saldo em conta corrente (\%PIB).

\begin{tabular}{c|c||c}
\hline Período & PII (milhões) & CC (\% PIB) \\
\hline 2003 & $-267,509$ & 0,7546 \\
\hline 2004 & $-291,607$ & 1,7595 \\
\hline 2005 & $-309,495$ & 1,5848 \\
\hline 2006 & $-360,011$ & 1,2530 \\
\hline 2007 & $-530,844$ & 0,1135 \\
\hline 2008 & $-275,312$ & $-1,7079$ \\
\hline 2009 & $-608,001$ & $-1,4949$ \\
\hline 2010 & $-936,819$ & $-2,2050$ \\
\hline 2011 & $-845,858$ & $-2,1201$ \\
\hline
\end{tabular}

\footnotetext{
${ }^{4}$ O cálculo da PII utiliza-se da metodologia da quinta edição do Manual de Balanço de Pagamentos do Fundo Monetário Internacional, publicado em 1993 (BPM5), de acordo com as notas explicativas do Banco Central do Brasil, disponível em: http://www.bcb.gov.br/ftp/infecon/NotasExplBPM5.pdf.
} 


\begin{tabular}{c||c||c}
\hline 2012 & $-851,856$ & $-2,4140$ \\
\hline 2013 & $-759,274$ & $-3,6564$ \\
\hline \hline
\end{tabular}

Fonte: Banco Central do Brasil e Ipea Data.

Notas: PII = Posição Internacional de Investimentos em milhões de dólares. $\mathrm{CC}=$ Saldo em Conta Corrente em $\%$ do PIB.

O saldo em transações correntes, ou saldo em conta corrente, corresponde ao somatório de três contas do balanço de pagamentos de um país - balança comercial, balança de serviços e rendas e transferências unilaterais ${ }^{5}$. Braga e Paulani (2007) afirmam que esse saldo representa um significado econômico importante ao país, pois, se o este envia mais recursos do que recebe ao exterior, há um déficit em transações correntes, enquanto que se recebe mais recursos do exterior do que envia, há um superávit em transações correntes.

Analisando os dados da tabela 1, para o período de 2003 a 2013 percebe-se que o Brasil vem incorrendo em recorrentes déficits na conta corrente, o que indica que têm enviado mais recursos ao exterior do que recebido. Para além, ao se analisar os dados da PII, nota-se que o Brasil acumula mais passivos externos do que ativos, além desta parcela de passivos estar aumentando significativamente ao longo da década. Logo, faz-se necessário observar a dinâmica e a composição dos fluxos financeiros direcionados a essa economia, uma vez que o papel dos fluxos registrados na conta financeira do balanço de pagamentos brasileiro torna-se muito importante, por um lado ao tentar compensar o déficit corrente e, por outro, ao indicar se tais recursos possuem um caráter mais produtivo ou não, podendo afetar a dinâmica e as variáveis macroeconômicas.

A conta financeira do balanço de pagamentos registra os fluxos transacionados entre ativos e passivos financeiros de residentes e não residentes de um país. Essa conta é divida em quatro grupos de transações, quais sejam Investimentos Diretos, Investimentos em Carteira, Derivativos e Outros Investimentos. Cada um desses grupos se subdivide ao registrar os fluxos envolvendo ativos externos detidos por residentes e o registro da emissão de passivos por residentes, cujo credor é não residente.

Seguindo a metodologia das Notas Técnicas do Banco Central do Brasil (2001), a conta Investimento Direto se divide em Investimento Direto no exterior (ativos externos detidos por residentes) e em Investimento Direto no país (passivos externos detidos por não residentes). As modalidades de investimento registradas nessa conta referem-se à participação no capital (referentes à aquisição, subscrição, aumento, total ou parcial do capital social de empresas) e a empréstimos intercompanhias (empréstimos entre as matrizes e suas filiais sediadas em países diferentes).

A conta Investimento em Carteira contempla os fluxos de ativos e passivos constituídos pela emissão de títulos de crédito negociados em mercados secundários de papéis. Dessa forma, os ativos representam as aplicações brasileiras em títulos estrangeiros,

\footnotetext{
${ }^{5}$ Braga e Paulani (2007) definem balanço de pagamentos como a conta onde são registradas todas as transações entre residentes e não residentes de um país num determinado período de tempo, podendo-se avaliar a situação econômica desse país em relação à economia mundial. A balança comercial registra a movimentação de mercadorias (exportações e importações). A balança de serviços e rendas agrega as transações de intangíveis, incluindo, dessa forma, as receitas e despesas com transportes, viagens internacionais, rendas de capita (remessa de juros e lucros), por exemplo. Já as transferências unilaterais representam pagamentos ou recebimentos, tanto em moeda quanto em bens, sem contrapartida (doações, por exemplo).
} 
enquanto os passivos contemplam as aquisições feitas por não residentes de títulos de emissão brasileira.

A conta Derivativos registra os fluxos referentes à liquidação de haveres e obrigações derivadas de operações de swap, opções e futuros e os fluxos relativos aos prêmios de opções. Esse instrumento financeiro tem seu preço derivado de um bem ou de outro instrumento financeiro. De maneira geral, as operações que envolvem derivativos financeiros têm como objetivos a proteção, alavancagem, especulação e arbitragem ${ }^{6}$.

Os ativos da conta Outros Investimentos correspondem às operações de empréstimos (empréstimos e financiamentos, de curto e longo prazo, do país a não residentes), moeda e depósitos (movimentações de depósitos mantidos no exterior como forma de disponibilidades, cauções, depósitos judiciais e garantias a empréstimos referentes às exportações) e outros ativos (correspondem à participação do país no capital de organismos internacionais e depósitos de cauções de longo prazo) de residentes no exterior, enquanto os passivos contemplam as operações de créditos comerciais, empréstimos, moeda e depósitos e outros passivos de estrangeiros no Brasil.

\section{Gráfico 1: Conta financeira do Brasil - segundo nível de abertura ${ }^{7}$ (U\$ milhões) - 2003 a 2013}

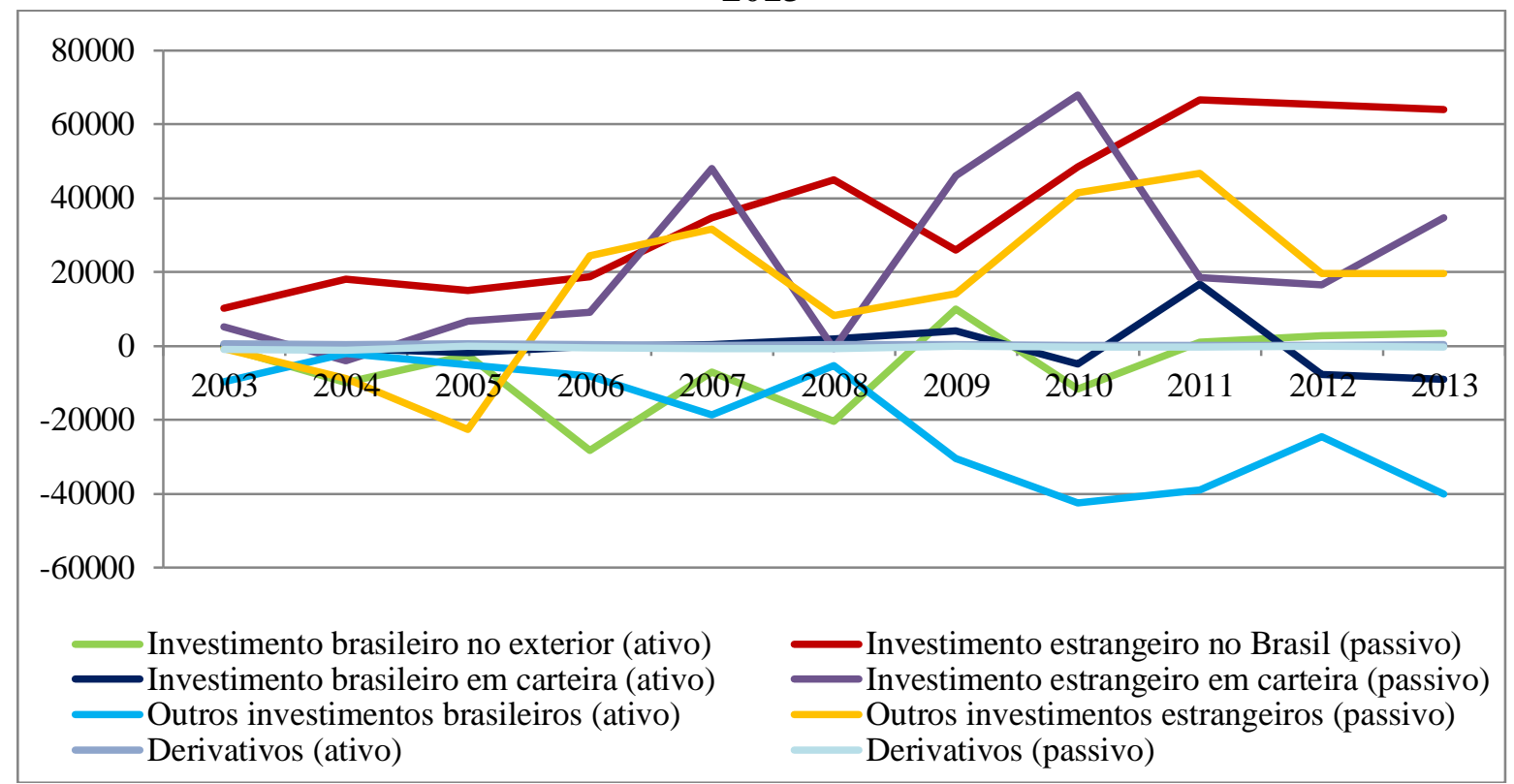

Fonte: Elaboração própria com base nos dados do Banco Central do Brasil.

Através do gráfico 1 é possível perceber mais claramente a magnitude dos fluxos financeiros transacionados no Brasil. Ao desagregar cada sub-conta da conta financeira do balanço de pagamentos em seus ativos e passivos, torna-se claro o movimento volátil destes fluxos no período em questão, sobretudo após o ano 2008, em que começa a se captar os efeitos da crise financeira desencadeada em 2007. Nota-se ainda que as sub-contas Investimento em Carteira (passivo) e Outros Investimentos (passivo) são mais voláteis que as

\footnotetext{
${ }^{6}$ Ver BM\&FBOVESPA.

${ }^{7}$ Atribui-se a expressão segundo nível de abertura para a desagregação das 4 sub-contas da conta financeira do balanço de pagamentos em suas modalidades ativo e passivo, tendo em vista que é possível ir além na desagregação dessas contas, ao discriminar as operações registradas em cada nível.
} 
demais, o que pode ser justificado pelo fato dos fluxos registrados nessas rubricas terem uma temporalidade de mais curto prazo e serem atraídos fortemente pelo diferencial de juros oferecido. Ademais, é notório o grande volume de recursos que o Brasil vem recebendo por meio da conta Investimento Direto, caracterizada por transacionar recursos de cunho mais produtivo e de mais longo prazo, o que é benéfico para a dinâmica econômica do país.

Rossi (2010) ao analisar as características gerais dos fluxos financeiros transacionados no Brasil no período de 1990 a 2006 aponta que os fluxos de Investimento Direto se apresentam mais estáveis que os demais, além de representarem recursos de melhor qualidade ao financiamento de países periféricos, apesar de que, no geral, o país se apresenta com um padrão de baixa qualidade de integração financeira, devido, sobretudo, ao grande estoque de passivos de portfólio acumulados e à alta volatilidade de fluxos deste tipo, sendo "certamente um aspecto negativo da integração financeira brasileira" (p. 119). Ressalta-se que a dimensão imediata desse aspecto negativo da integração financeira se dá no comportamento da taxa de câmbio dessas economias, uma vez que países com pior perfil de integração financeira tendem a apresentar maior volatilidade nas taxas de câmbio e juros.

Portanto, é possível perceber uma relação dos fluxos financeiros sobre os movimentos da taxa de câmbio, uma vez que "a liberdade dos fluxos de capitais gera grandes movimentos nas taxas de câmbio e, com isso, a política monetária fica refém dessa volatilidade" (ROSSI, 2010, p. 129). Mas, há, também, o efeito dos movimentos da taxa de câmbio sobre os fluxos de capitais, já que a taxa de câmbio, sendo o valor de referência para os investidores externos, ao se comportar de maneira volátil, torna também voláteis o valor dos contratos entre residentes e não-residentes. Assim, nota-se uma dupla determinação entre os movimentos da taxa de câmbio e dos fluxos financeiros, em que "países com taxas de câmbio e juros voláteis tendem a ter um padrão de baixa qualidade e, não custa dizer, por ter um padrão de baixa qualidade tendem a ter taxas voláteis" (ROSSI, 2010, p. 130).

Munhoz e Libânio (2009) ao analisarem a volatilidade dos fluxos financeiros direcionados à economia brasileira apontam que no período de 1999 a 2008 os fluxos de capitais mais flexíveis dominaram o balanço de pagamentos do país, sendo estes condicionados pelos movimentos de liquidez internacional, no sentido de que, a qualquer mudança de expectativa, seu caráter especulativo vem à tona, já que apresentam movimentos de reversão, exemplificado pelo período que capta os efeitos inicias da crise financeira de 2007. Ademais, o trabalho desses autores vai ao encontro da análise dos dados expostos no gráfico 1 acima, em que as sub-contas mais expressivas dessa volatilidade são Investimento em Carteira e Outros Investimentos. Logo:

Ainda mais importante, os episódios de crise mais recentes, como a crise do mercado de Subprime nos Estados Unidos, que se instalou em 2007, mostram que a volatilidade dos fluxos de capitais direcionados à economia brasileira torna-se ainda mais alta. O início de 2008 mostra como já havia ocorrido uma fuga de capitais do Brasil (via Investimentos em Carteira e Outros Investimentos, principalmente), como conseqüência desta crise. No final daquele ano a fuga, através de Investimentos Estrangeiros em Carteira e Outros Investimentos Estrangeiros, foi ainda mais intensa, mostrando que a vulnerabilidade externa estava posta. Portanto, as contas mais voláteis e que geram fortes fugas de capitais são justamente aquelas que apresentam maior viés especulativo (MUNHOZ, LIBÂNIO, 2009, p. 16).

Econ. e Desenv., Santa Maria, vol. 26, n.2, p. 85 - 106, jul. - dez. 2014 
O que se tem, em resumo, é uma situação na qual enquanto há forte liquidez internacional os fluxos financeiros se dirigem fortemente a economias emergentes, como a brasileira, ao passo que, diante de um episódio de reversão de expectativas, como a crise financeira mostrou, estes capitais instauram um movimento de fuga. Tal movimento volátil e instável traz conseqüências imediatas às variáveis macroeconômicas, principalmente a taxa de câmbio, já que ela "apresenta-se sobrevalorizada diante do enorme influxo de recursos internacionais e sofre um overshooting em momentos de fuga de capitais" (MUNHOZ, LIBÂNIO, 2010, p. 26).

De modo similar aos demais trabalhos, Munhoz (2013) se vale das discussões recentes sobre a adoção de medidas de controle à entrada de capitais no Brasil, tendo a ideia de que esta economia está sujeita à vulnerabilidade externa, e busca investigar a inter-relação entre taxa de câmbio, fluxos de capitais, IOF (imposto sobre operações financeiras), juros e riscopaís. A hipótese subjacente ao trabalho é de que os fluxos financeiros são fortemente associados a variáveis que representam a lógica da rentabilidade dos investidores, gerando forte especulação e impactos na taxa de câmbio. Os resultados apontam que o IOF, principal instrumento de controle de capital utilizado pelo Brasil, não conseguiu constituir uma barreira forte aos movimentos de capitais, sobretudo os de curto prazo. Ademais, e com maior relevância à nossa análise, o estudo revela que a consequência do boom de influxos apresentada na última década levou à forte apreciação da moeda brasileira nos últimos anos e, esses movimentos demonstram o caráter pró-cíclico dos fluxos de capitais sobre os movimentos da taxa de câmbio, bem como o efeito do câmbio sobre os influxos financeiros.

De maneira semelhante ao objetivo proposto neste trabalho, Munhoz e Veríssimo (2013) analisam a importância relativa tanto de variáveis comerciais quanto financeiras na explicação da tendência de apreciação da taxa de câmbio brasileira utilizando a metodologia VAR. As autoras apontam que os fluxos de capitais foram selecionados para analisar a taxa de câmbio devido à sua abundância poder provocar valorização cambial enquanto que em momentos de crise, com a saída abrupta, há pressão pela desvalorização do câmbio. Para além, destacam a relação do câmbio capaz de influenciar a entrada destes fluxos, já que essa taxa representa um elemento importante de retorno e referência para os investidores externos. Logo, "argumenta-se que há uma relação dinâmica entre fluxos de capitais de curto prazo e taxa de câmbio no Brasil, que pode explicar a volatilidade cambial nos últimos anos" (MUNHOZ e VERÍSSIMO, 2013, p. 12). Os resultados apresentados pelas autoras apontam efeitos robustos sobre a taxa de câmbio através dos choques de preço das commodities, pelo lado comercial, e das entradas de investimento em carteira e risco-país, pelo lado financeiro, o que indica que a dinâmica da taxa de câmbio está sujeita tanto às transações pelo lado do comércio internacional quanto às transações financeiras internacionais. "Neste sentido, os movimentos recentes de câmbio praticamente independem das condições econômicas domésticas" (MUNHOZ e VERÍSSIMO, 2013, p. 18).

É neste contexto que esse trabalho se justifica, ao procurar buscar as relações existentes entre o comportamento dos fluxos financeiros e a taxa de câmbio, além da análise em sentido contrário. Vale destacar que, como analisado anteriormente, os fluxos registrados na sub-conta Investimento em Carteira possuem uma temporalidade de mais curto prazo e, consequentemente, um perfil mais especulativo. Dessa maneira, a análise da metodologia VAR procurará também analisar os efeitos das modalidades de investimento estrangeiro no 
Brasil dessa sub-conta, representadas por fluxos de renda fixa e ações de companhias brasileiras, de modo a analisar as relações destas com a taxa de câmbio.

\section{Metodologia e variáveis}

O objetivo deste trabalho consiste em investigar a relevância das variáveis financeiras ligadas aos fluxos internacionais de capitais para explicar o comportamento da taxa de câmbio real brasileira ao longo da última década. Para tanto será utilizada a metodologia de vetores auto-regressivos (VAR).

O VAR é uma extensão de um modelo univariado auto-regressivo para séries temporais multivariadas. O modelo é constituído por um sistema de equações lineares dinâmicas, em que cada variável é representada como função de um erro serialmente não correlacionado e, todas as variáveis pertencentes ao sistema possuem o mesmo número de defasagens (Bueno, 2008).

Essa metodologia trata todas as variáveis analisadas como endógenas, formando um sistema de equações estimadas por Mínimos Quadrados Ordinários (MQO). Assim, o VAR se mostra útil para a análise das interações propostas neste trabalho, já que possibilita observar as relações dinâmicas entre as variáveis endógenas consideradas, sem a necessidade de se definir previamente a causalidade entre elas. Neste sentido, os resultados da modelagem VAR utilizada neste trabalho serão apresentadas através da estimação da Função de Resposta aos Impulsos, em que se verifica o sentido dos efeitos de cada variável (impulso) sobre as demais (resposta), e, através da decomposição da variância, em que se procura a porcentagem da variância de erro de previsão decorrente de cada variável endógena. A escolha pela apresentação dos resultados através destas duas modalidades se dá devido ao tipo de resultado que busca-se analisar. Deste modo, a decomposição da variância auxilia na descrição da dinâmica do sistema na abordagem VAR, tornando possível identificar a proporção da variação total de uma variável produzida devido a cada choque individual nas $k$ variáveis componentes do modelo. Já a Função de Resposta aos Impulsos apresenta o comportamento das séries incluídas no modelo VAR em resposta a choques ou mudanças provocadas por variáveis residuais.

O modelo aqui proposto compreende as seguintes variáveis: taxa de câmbio real (TXCR), investimento estrangeiro em carteira (IEC), investimento estrangeiro direto (IED), derivativos (DER), outros investimentos estrangeiros (OIE), ações de companhias brasileiras (ACB), ações de renda fixa (ARF), risco país (EMBI), inflação (IPCA) e taxa de juros (TXJUROS). O intuito é analisar as relações existentes entre a taxa de câmbio brasileira e os fluxos financeiros que ingressam no país, sendo assim representados pelas sub-contas IEC, IED, DER e OIE, todas medidas através do o ingresso dos fluxos. Destaca-se que, em virtude da sub-conta IEC representar maior volatilidade, como apresentado no gráfico 1 da seção anterior e também pelos trabalhos empíricos analisados, foram selecionadas as sub-contas em terceiro nível de desagregação dessa rubrica que representam tais fluxos, sendo elas ACB e ARF. Ademais, a escolha do risco país, inflação e taxa de juros ao modelo se dão pela influência direta que estas variáveis exercem sobre a taxa de câmbio.

Econ. e Desenv., Santa Maria, vol. 26, n.2, p. 85 - 106, jul. - dez. 2014 
À exceção dos dados do risco país que foram retirados do portal do Ipea (Ipea-Data), todos os outros foram retirados do sistema gerenciador de séries temporais do Banco Central do Brasil, sendo listado a seguir o número de cada série: (ACB) série ${ }^{\circ} 2885$; (ARF) série $\mathrm{n}^{\circ}$ 8223; (DER) série $n^{\circ}$ 2902; (IEC) série $n^{\circ}$ 8215; (IED) série $n^{\circ} 8196$; (IPCA) série $n^{\circ} 433$; (OIE) série $\mathrm{n}^{\circ} 2914$; (TXCR) série $\mathrm{n}^{\circ} 3697$ e (TXJUROS) série $\mathrm{n}^{\circ} 4390$. A periodicidade dos dados coletados é mensal, sendo que para o risco país foi realizada a média mensal, uma vez que os dados coletados originalmente possuem a temporalidade diária. O período analisado compreende o mês de Janeiro de 2003 a dezembro de 2013. A modelagem VAR foi feita a partir do software econométrico Eviews 4.1.

\section{Resultados}

A tabela 2 apresenta as estatísticas descritivas das variáveis utilizadas na modelagem VAR. Observa-se que as variáveis que representam os fluxos financeiros apresentam fortes oscilações no período, apontando grande discrepância em relação aos seus valores máximo e mínimo, indicando a instabilidade inerente a essas variáveis. Destaca-se, sobretudo, as subcontas que carregam um perfil mais especulativo, tendo a OIE valor máximo de 13152.30 e mínimo de -12387.80 e, a IEC máximo de 319838.0 e mínimo de 1095.100.

Tabela 2: Estatísticas Descritivas

\begin{tabular}{c|c|c|c|c|c}
\hline \hline & Média & Mediana & Máximo & Mínimo & Desvio-Padrão \\
\hline ACB & 7847.613 & 7227.900 & 36217.90 & 42.10000 & 6099.291 \\
\hline ARF & 3879.667 & 3200.150 & 17187.40 & 400.3000 & 2886.764 \\
\hline DER & 28.52424 & 21.45000 & 433.1000 & -222.8000 & 59.24048 \\
\hline EMBI & 2.285786 & 1.580150 & 8.971900 & 0.858300 & 1.590602 \\
\hline IEC & 14178.77 & 11377.75 & 319838.0 & 1095.100 & 27987.88 \\
\hline IED & 4803.866 & 4143.300 & 19792.70 & 911.0000 & 3189.364 \\
\hline IPCA & 0.475985 & 0.460000 & 2.250000 & -0.210000 & 0.303813 \\
\hline OIE & 1313.369 & 960.0000 & 13152.30 & -12387.80 & 3730.018 \\
\hline TXCR & 2.175864 & 2.072200 & 3.590000 & 1.563100 & 0.469084 \\
\hline TXJUROS & 1.038333 & 0.950000 & 2.080000 & 0.490000 & 0.352356 \\
\hline \hline
\end{tabular}

Fonte: Saída do Eviews 4.1.

Outra variável que merece atenção é a referente aos investimentos diretos no Brasil, que apontam um máximo de 19792.7 e mínimo de 911.0, tendo a média de 4803.866, o que confirma a análise feita na seção anterior referente ao grande montante de recursos que o Brasil vem recebendo nesta rubrica.

Para além, através da tabela 2 é possível analisar o quanto a rubrica que registra os fluxos da sub-conta derivativos é menos expressiva que as demais, apresentando uma média de 28.52, enquanto apenas uma das modalidades da IEC, representada pelas ACB apresenta média de 7847.613. Merece destaque também a variável risco país, uma vez que seu máximo de 8.97 não é regra, já que sua média é de 2.28, o que demonstra melhores avaliações por parte do investidor externo da economia brasileira no período em questão.

A tabela 3 apresenta os testes de estacionariedade das séries do modelo VAR. Segundo Gujarati (2006), um processo estocástico é estacionário se suas médias e variância forem 
constantes ao longo do tempo e se o valor da covariância entre os dois períodos de tempo depender apenas da distância ou defasagem entre os dois períodos e não do período de tempo efetivo em que a covariância é calculada. O teste mais utilizado é o Argumented DickeyFuller $(A D F)$, entretanto, para garantir-se maior segurança nos resultados, foram realizados ainda os testes Phillips-Perron (PP), Kwiatkowski-Phillips-Schmidt-Shin (KPSS) e o DickeyFuller GLS (DF-GLS). Vale ressaltar que a hipótese nula dos testes ADF, PP e DF-GLS é de que a série possui raiz unitária, sendo assim, não estacionária. Já o teste KPSS tem como hipótese nula a série não possuir raiz unitária e, dessa forma ser estacionária.

Tabela 3: Testes de Estacionariedade

\begin{tabular}{|c|c|c|c|c|}
\hline & ADF & $\mathbf{P P}$ & KPSS & DF - GLS \\
\hline DACB & $\mathrm{a}$ & $\mathrm{a}$ & $\mathrm{a}$ & $\mathrm{c}$ \\
\hline T-stat & $-18.12417(* * *)$ & $-20.26884(* * *)$ & $0.069696(* * *)$ & $-18.04886(* * *)$ \\
\hline Prob & 0.0000 & 0.0000 & - & - \\
\hline ARF & $\mathrm{b}$ & $\mathrm{a}$ & $\mathrm{a}$ & $\mathrm{c}$ \\
\hline t-stat & $-2.634739(*)$ & $-6.072617(* * *)$ & $0.122090(* *)$ & $-1.742819(*)$ \\
\hline Prob & 0.0887 & 0.0000 & - & - \\
\hline DER & $\mathrm{a}$ & $\mathrm{a}$ & $\mathrm{a}$ & $\mathrm{c}$ \\
\hline t-stat & $-13.02292(* * *)$ & $-13.02292(* * *)$ & $0.077808(* * *)$ & $-13.11966(* * *)$ \\
\hline Prob & 0.0000 & 0.0000 & - & - \\
\hline $\begin{array}{c}\text { DEMBI } \\
\text { t-stat }\end{array}$ & $\begin{array}{c}\mathrm{a} \\
-11.91915(* * *)\end{array}$ & $\begin{array}{c}\mathrm{a} \\
-23.17158(* * *)\end{array}$ & $\begin{array}{c}\mathrm{a} \\
0.130735(* *)\end{array}$ & $\begin{array}{c}\mathrm{c} \\
-12.00418(* * *)\end{array}$ \\
\hline Prob & 0.0000 & 0.0000 & - & $\begin{array}{c}12.00+101 \\
-\end{array}$ \\
\hline IEC & $\mathrm{a}$ & $\mathrm{a}$ & $\mathrm{a}$ & $\mathrm{c}$ \\
\hline t-stat & $-10.98939(* * *)$ & $-10.98939(* * *)$ & $0.074509(* * *)$ & $-11.05839(* * *)$ \\
\hline Prob & 0.0000 & 0.0000 & - & - \\
\hline IED & $\mathrm{a}$ & $\mathrm{a}$ & $\mathrm{a}$ & $\mathrm{c}$ \\
\hline t-stat & $-11.54555(* * *)$ & $-11.86938(* * *)$ & $0.057409(* * *)$ & $-11.29757(* * *)$ \\
\hline Prob & 0.0000 & 0.0000 & - & - \\
\hline DIPCA & $\mathrm{a}$ & $\mathrm{a}$ & $\mathrm{a}$ & $\mathrm{c}$ \\
\hline t-stat & $-11.66388(* * *)$ & $-13.46061(* * *)$ & $0.065059(* * *)$ & 0.218889 \\
\hline Prob & 0.0000 & 0.0000 & - & - \\
\hline OIE & $\mathrm{a}$ & $\mathrm{a}$ & $\mathrm{a}$ & $\mathrm{c}$ \\
\hline t-stat & $-8.878964(* * *)$ & $-8.864360(* * *)$ & $0.092684(* * *)$ & $-8.937624(* * *)$ \\
\hline Prob & 0.0000 & 0.0000 & - & - \\
\hline DTXCR & $\mathrm{a}$ & $\mathrm{a}$ & $\mathrm{a}$ & $\mathrm{c}$ \\
\hline t-stat & $-8.437784(* * *)$ & $-8.460679(* * *)$ & $0.026996(* * *)$ & $-5.471472(* * *)$ \\
\hline Prob & 0.0000 & 0.0000 & - & - \\
\hline DTXJUROS & $\mathrm{a}$ & $\mathrm{a}$ & $\mathrm{a}$ & $\mathrm{c}$ \\
\hline t-stat & $-3.783286(* * *)$ & $-19.39300(* * *)$ & $0.099804(* * *)$ & -0.091018 \\
\hline Prob & 0.0208 & 0.0000 & - & - \\
\hline
\end{tabular}

Fonte: Elaboração própria a partir da saída do Eviews 4.1.

Nota 1: Presença de intercepto e tendência (a); presença de constante (b); sem constante e tendência (c).

Nota 2: Estacionário a $1 \%(* * *)$; Estacionária a 5\% (**); Estacionária a 10\% (*).

A série de ações de companhias brasileiras (ACB), risco país (EMBI), inflação (IPCA), taxa de câmbio real (TXCR) e taxa de juros (TXJUROS) apresentaram raiz unitária, sendo não estacionárias em nível. Dessa forma, estas séries foram utilizadas em sua primeira diferença, passando às seguintes denominações (DACB), (DEMBI), (DIPCA), (DTXCR) e (DTXJUROS). A série (ARF) apresentou estacionariedade a $1 \%$ no teste PP; a (DER) 
apresentou estacionariedade a $1 \%$ em todos os testes feitos, assim como as séries (IEC), (IED) e (OIE).

Após a realização dos testes de estacionariedade partiu-se para a especificação e escolha da defasagem do modelo VAR, observado pela tabela 4. De acordo com os valores apresentados pelo procedimento LAG CRITERIA, foi escolhido um modelo com duas defasagens, sendo representado por VAR (2), já que os menores valores apresentados pelos critérios de informação da Akaike e Hannan-Quinn apontavam para tal especificação.

Tabela 4: Seleção do Modelo VAR

Variáveis Endógenas: DACB, ARF, DER, DEMBI, IEC, IED, DIPCA, OIE, DTXCR, DTXJUROS

Variável Exógena: C

\begin{tabular}{ccccccc}
\hline Defasagem & LogL & LR & FPE & AIC & SC & HQ \\
\hline \hline 0 & -6888.641 & NA & $7.19 \mathrm{E}+34$ & 108.6400 & $108.8640^{*}$ & 108.7310 \\
1 & -6661.798 & 414.3907 & $9.80 \mathrm{E}+33$ & 106.6425 & 109.1060 & 107.6434 \\
2 & -6486.001 & 293.4554 & $3.05 \mathrm{E}+33^{*}$ & $105.4488^{*}$ & 110.1518 & $107.3596^{*}$ \\
3 & -6390.343 & 144.6172 & $3.50 \mathrm{E}+33$ & 105.5172 & 112.4597 & 108.3379 \\
4 & -6287.944 & $138.6823^{*}$ & $3.88 \mathrm{E}+33$ & 105.4794 & 114.6615 & 109.2100 \\
\hline \hline
\end{tabular}

Fonte: Saída do Eviwes 4.1.

* indica a ordem da defasagem pelo critério de seleção

AIC: Critério de Informação de Akaike; SC: Critério de Informação de Schwarz;

SC: Critério de Informação de Schwarz

HQ: Critério de Informação de Hannan-Quinn

Figura 1: Estabilidade do modelo VAR (2)

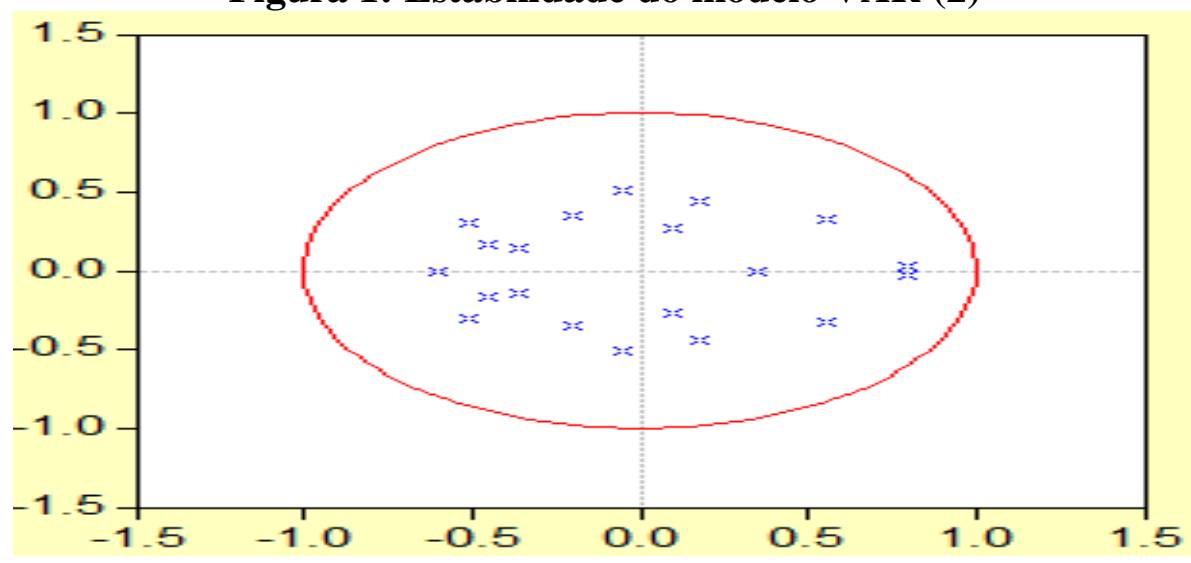

Fonte: Saída do Eviews 4.1.

Na sequência, foi estimado o modelo VAR (2) e testada sua estabilidade, através da análise $A R$ ROOTS, representada pela figura 1. Como se nota, todas as representações em forma de ' $x$ ' se encontram dentro da demarcação do círculo, que representa a delimitação de raiz unitária, logo, o modelo VAR (2) é estável.

Em seguida, realizou-se o teste de autocorrelação. A autocorrelação é entendida como a correlação entre as variáveis da série e pode ocorrer, dentre outros motivos, devido à inércia, viés de especificação do modelo, defasagens, transformação dos dados, além da ausência de estacionariedade. Na presença de autocorrelação há viés nos estimadores e, subestima-se a variância residual, assim como o erro padrão, o que leva também a problemas na interpretação dos testes de significância, t e F (GUJARATI, 2006). 
Um dos testes mais utilizados para se detectar a presença de autocorrelação é o de Breusch-Godfrey (Serial Correlation LM test), sendo que, considerando o nível de significância de $5 \%$, se o p-valor for maior que 0,05 não se rejeita a hipótese nula de inexistência de autocorrelação, enquanto que se o p-valor for menor que 0,05 rejeita-se a hipótese nula e, portanto, há autocorrelação.

Tabela 5: Teste de autocorrelação (teste LM) - VAR(2)

H0: não há correlação serial na defasagem de ordem h

\begin{tabular}{ccc} 
Defasagem & LM-Stat & Prob \\
\hline \hline 1 & 147.7964 & 0.0013 \\
2 & 167.7996 & 0.0000 \\
3 & 103.1471 & 0.3946 \\
4 & 118.6807 & 0.0980 \\
5 & 107.5062 & 0.2861 \\
6 & 92.50083 & 0.6903 \\
7 & 122.8226 & 0.0604 \\
8 & 116.5586 & 0.1234 \\
9 & 80.12829 & 0.9282 \\
10 & 125.4308 & 0.0435 \\
11 & 78.02900 & 0.9491 \\
12 & 140.5293 & 0.0047 \\
\hline \hline
\end{tabular}

Fonte: Saída do Eviwes 4.1.

*Probabilidades a partir de Qui-quadrados com 16 defasagens

Neste caso, ao se analisar a tabela 5 nota-se que o VAR (2) apresenta auto-correlação, devido ao p-valor ser menor que 0,05 , o que não garante tanta confiabilidade às estatísticas $\mathrm{t} e$ $\mathrm{F}$, assim como a eficiência do modelo. Dessa forma, optou-se por aumentar as defasagens do modelo de duas para cinco, sendo assim, passa-se para um VAR (5).

Dessa forma, testou-se a estabilidade do modelo VAR (5). Na figura 2, através da análise AR ROOTS, se nota que todas as representações em forma de ' $\mathrm{x}$ ' se encontram dentro da demarcação do círculo, indicando que o modelo VAR (5) é estável.

Figura 2: Estabilidade do modelo VAR (5)

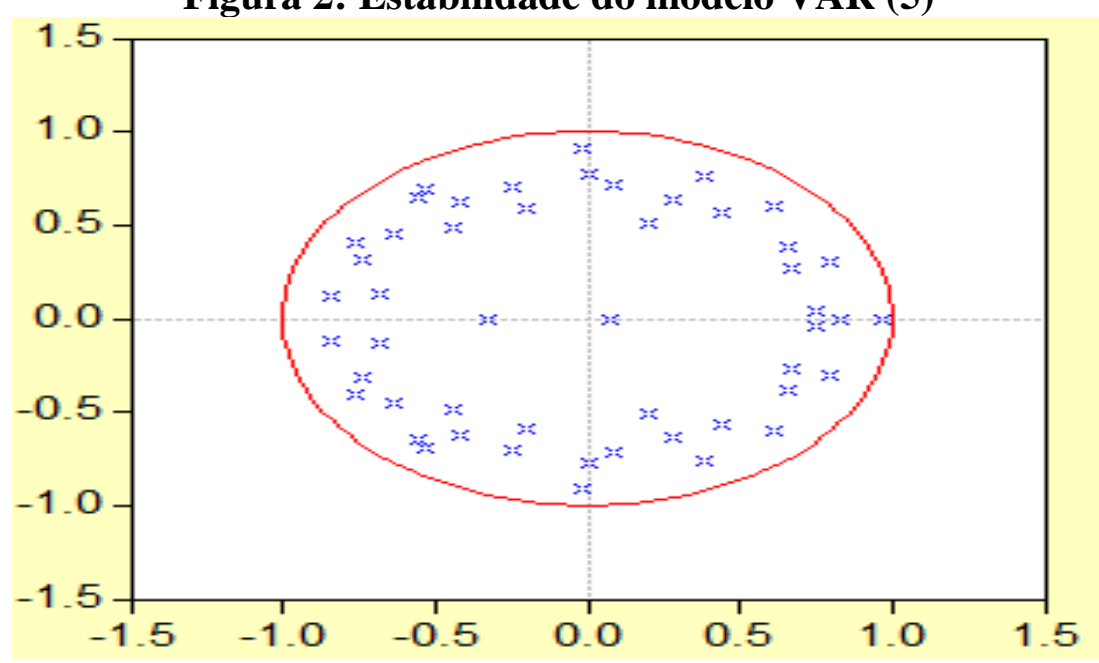

Fonte: Saída do Eviews 4.1.

Econ. e Desenv., Santa Maria, vol. 26, n.2, p. 85 - 106, jul. - dez. 2014 
Tabela 6: Teste de autocorrelação (teste LM) - VAR(5)

H0: não há correlação serial na defasagem de ordem h

\begin{tabular}{ccc} 
Defasagem & LM-Stat & Prob \\
\hline \hline 1 & 97.71501 & 0.5460 \\
2 & 95.93586 & 0.5964 \\
3 & 114.2006 & 0.1570 \\
4 & 101.4683 & 0.4402 \\
5 & 119.3247 & 0.0912 \\
6 & 92.06274 & 0.7017 \\
7 & 94.47380 & 0.6371 \\
8 & 83.17145 & 0.8881 \\
9 & 94.96794 & 0.6235 \\
10 & 115.8791 & 0.1324 \\
11 & 100.9289 & 0.4552 \\
12 & 97.24880 & 0.5593 \\
\hline
\end{tabular}

Fonte: Saída do Eviwes 4.1.

*Probabilidades a partir de Qui-quadrados com 16 defasagens

Pode-se observar na tabela 6 que no novo modelo VAR, agora com cinco defasagens, o problema da autocorrelação foi resolvido, sendo o novo modelo ausente de autocorrelação, já que o p-valor é maior que 0,05 .

Em seguida foi feita a análise do modelo VAR (5) através da estimação das funções de impulso-resposta, que segundo Bueno (2008) medem o sentido dos efeitos de cada variável sobre as demais. A figura 3 abaixo apresenta as respostas da taxa de câmbio real (DTXCR) aos impulsos das demais séries utilizadas. Para além, na figura 4 busca-se analisar as respostas das séries representativas dos fluxos financeiros aos impulsos da taxa de câmbio. 


\section{Figura 3: Função de Resposta aos Impulsos}
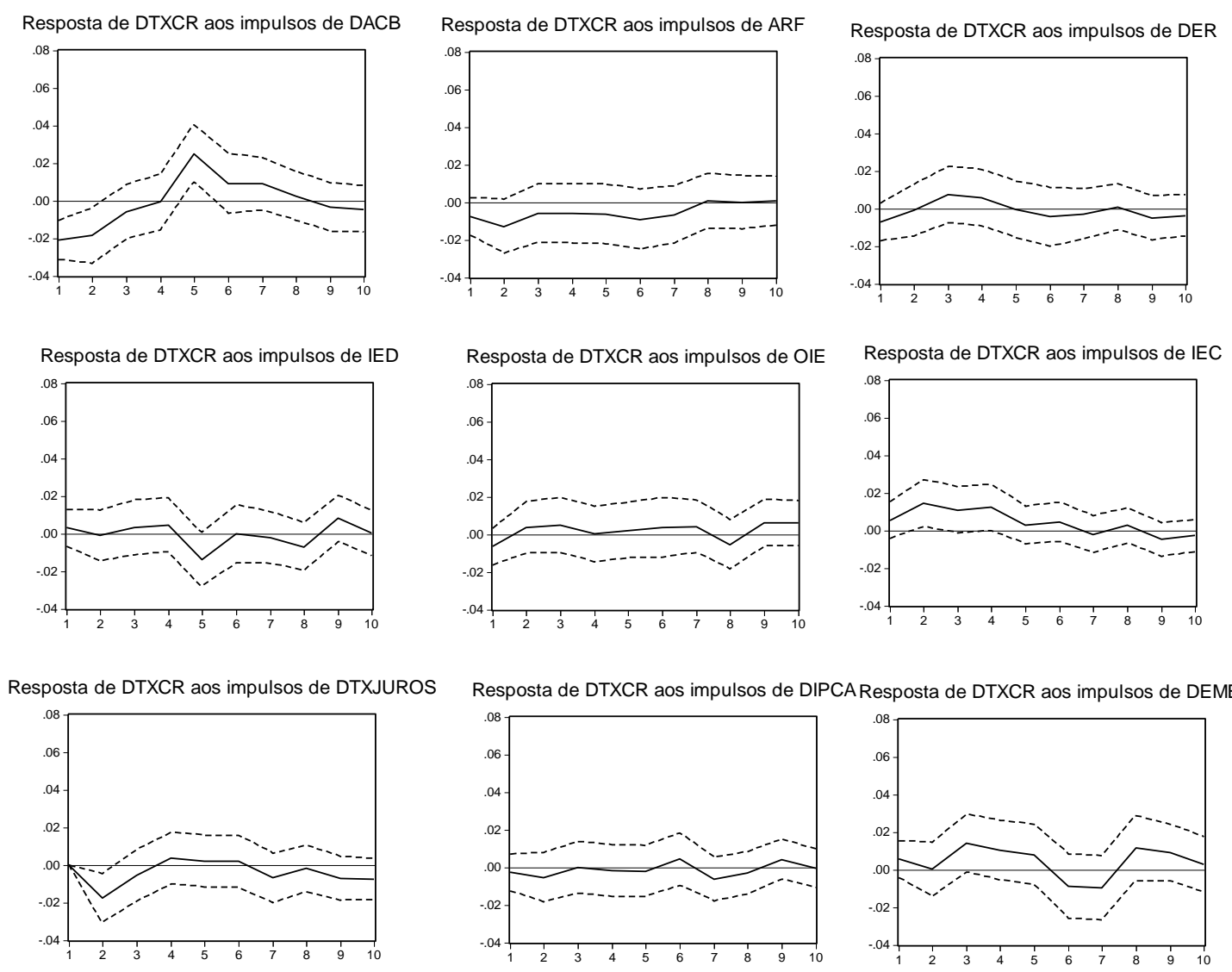

Fonte: Saída do Eviews 4.1.

Através da análise da figura $3^{8}$ pode-se perceber que a taxa de câmbio reponde de maneira significativa aos impulsos das demais variáveis do modelo. Primeiramente, quanto aos impulsos da série taxa de juros sobre a taxa de câmbio, a relação posta é negativa no sentido de que um aumento dos juros tende a apreciar a taxa de câmbio. Isto faz sentido já que um aumento dos juros faz com que a atratividade dos investimentos locais aumente e o ingresso de capitais externos faz com que a moeda local se aprecie. Quanto aos impulsos da série da inflação e do risco país a resposta do câmbio é no sentido positivo, o que indica que um aumento da inflação ou o aumento da percepção de risco por parte dos investidores internacionais tendem a depreciar a taxa de câmbio.

Ao centrar a análise para as séries financeiras do modelo, tem-se que na maior parte do período analisado a taxa de câmbio responde negativamente aos impulsos dos fluxos financeiros o que indica que, por exemplo, um ingresso maior de investimento direto, investimento em carteira, derivativos e outros investimentos tendem a apreciar a taxa de câmbio. Ademais, ao observar os impulsos das sub-contas de ingresso de ações de companhias brasileiras e ações de renda fixa vê-se claramente o quanto a taxa de câmbio tende a se apreciar, o que indica, conforme as análises feitas nas seções anteriores, que os

\footnotetext{
${ }^{8}$ Ressalta-se que a análise das funções de impulso resposta deve basear-se no sentido do pontilhado observado na figura 3, caso positivo ou negativo.
} 
fluxos financeiros de mais curto prazo tendem a exercer forte influência do comportamento da taxa de câmbio.

\section{Figura 4: Função de Resposta aos Impulsos}
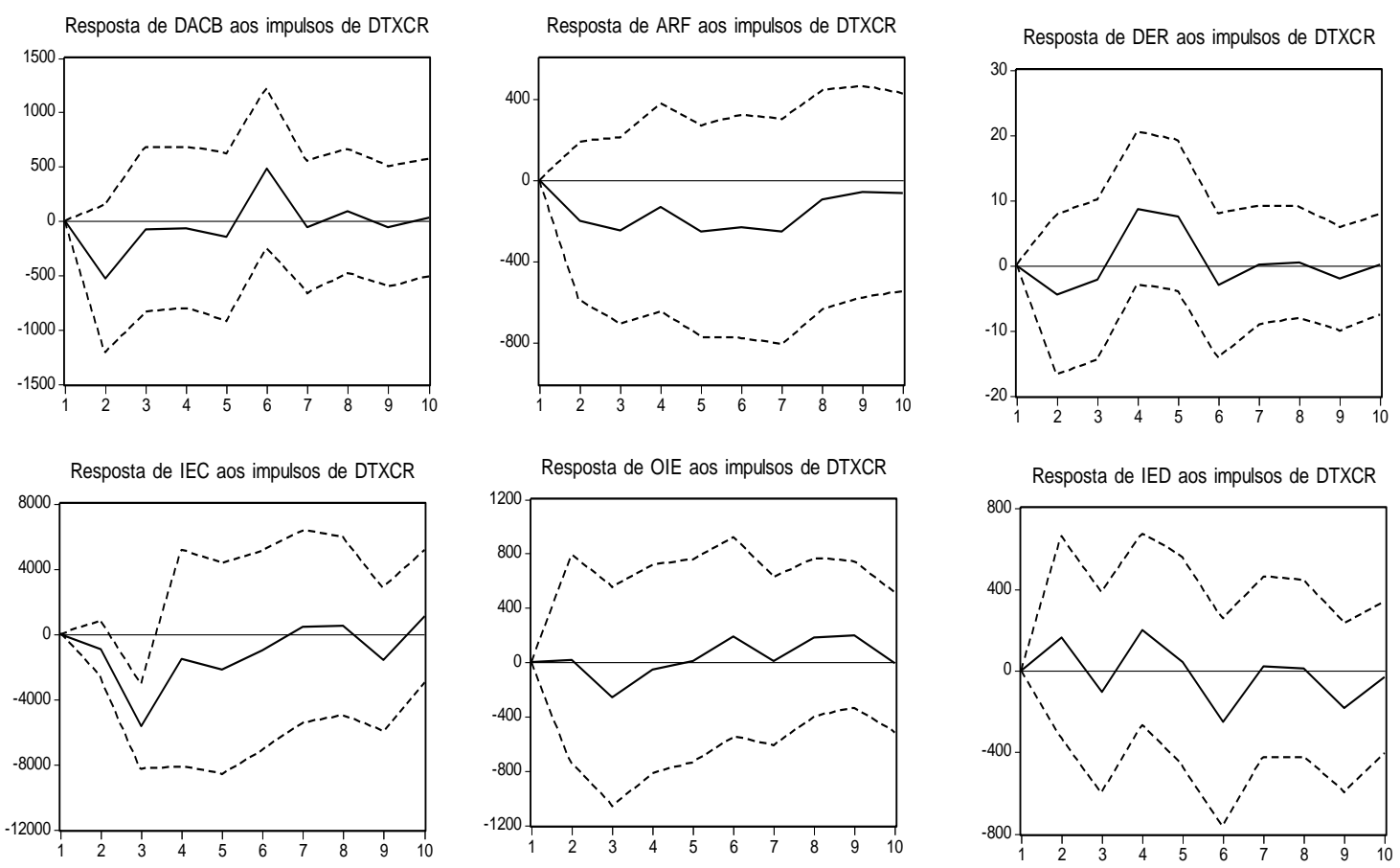

Fonte: Saída do Eviews 4.1.

$\mathrm{Na}$ figura 4 têm-se a análise da resposta das séries financeiras do modelo sobre os impulsos da taxa de câmbio, no sentido de se analisar a relação que esta taxa exerce no ingresso de capitais externos. Percebe-se que a resposta das séries financeiras aos impulsos da taxa de câmbio, se dá, na maior parte do período, no sentido positivo, ou seja, um aumento da taxa de câmbio, que se traduz em depreciação cambial, tende a estimular o ingresso de capitais externos, sendo que as sub-contas IEC, assim como em sua desagregação em DACB e ARF, são as mais características deste movimento. Isto faz sentido uma vez que os investidores externos utilizam a taxa de câmbio como uma variável de referência para realizarem suas inversões, sendo que quanto menos tiverem que converter para investir no país, em termos de moeda, por exemplo, quanto menos dólares precisarem trocar para comprar o real, melhor será a atratividade do investimento.

Em relação à análise da decomposição da variância, que corresponde à porcentagem da variância de erro de previsão decorrente de cada variável endógena do modelo, observa-se que, diferentemente da análise da resposta aos impulsos, o sentido dos efeitos não é o mais importante, mas sim o valor relativo dos efeitos de cada variável sobre o erro de previsão das demais variáveis. 
Figura 5: Análise da decomposição da variância (DTXCR) - (\%)

\begin{tabular}{|c|c|c|c|c|c|c|c|c|c|c|c|}
\hline Period & S.E. & DACB & ARF & DER & DEMBI & IEC & IED & DIPCA & OIE & DTXCR & DTXJUROS \\
\hline 1 & 3248.705 & 11.94660 & 1.583730 & 1.374788 & 1.243607 & 0.442787 & 0.073409 & 0.154574 & 1.338067 & 81.84244 & 0.000000 \\
\hline 2 & 3763.647 & 16.18485 & 4.661023 & 1.058661 & 1.128684 & 4.332779 & 0.055849 & 0.778824 & 1.261960 & 64.16639 & 6.370988 \\
\hline 3 & 3979.418 & 15.30301 & 4.858336 & 1.921211 & 5.474967 & 4.982837 & 0.517908 & 0.707994 & 1.563240 & 58.29377 & 6.376730 \\
\hline 4 & 4294.171 & 14.19898 & 5.151049 & 2.347836 & 7.685394 & 6.249884 & 0.931082 & 0.720152 & 1.455254 & 55.12698 & 6.133397 \\
\hline 5 & 4398.218 & 21.44447 & 5.063272 & 2.030313 & 7.732855 & 5.397639 & 3.084696 & 0.705051 & 1.719403 & 47.48428 & 5.338030 \\
\hline 6 & 4541.236 & 21.61341 & 6.031030 & 2.235502 & 8.315203 & 5.676871 & 2.946109 & 0.895697 & 1.811950 & 45,33428 & 5.139952 \\
\hline 7 & 4579.035 & 21.66310 & 6. 376728 & 2.264738 & 9.272967 & 5.409639 & 2.861016 & 1.451396 & 1.905824 & 43.23826 & 5.556329 \\
\hline 8 & 4669.406 & 21,04890 & 6.179432 & 2.199453 & 10.92535 & 5.238198 & 3.529359 & 1.500616 & 1.974687 & 41.96777 & 5.436226 \\
\hline 9 & 4756.379 & 20.35382 & 5.932351 & 2.472183 & 11.09731 & 5.595677 & 4.557319 & 1.608217 & 2.139092 & 40.34397 & 5.900063 \\
\hline 10 & 4795.277 & 20.16418 & 5.806664 & 2.605683 & 10.87884 & 5.611388 & 4.487198 & 1.585644 & 2.497387 & 39.88896 & 6.474052 \\
\hline
\end{tabular}

Fonte: Saída do Eviews 4.1.

Na figura 5 é expressa a análise da decomposição da variância da taxa de câmbio real em relação às demais variáveis. Como esperado, vê-se que a maioria da variância de previsão de uma variável é explicada pelos choques à própria variável, sendo a taxa de câmbio explicada em 39,88\% aproximadamente por si mesma. Destaca-se a série DACB que compreende $20,16 \%$ da variância da taxa de câmbio, seguida da conta representativa do risco país que contempla 10,87\% dessa variância. Para além, a série DER capta apenas 2,60\% da variância do câmbio, o que pode ser explicado devido a pouca relevância do montante desses fluxos no Brasil, quando comparados às demais sub-contas financeiras.

Tabela 7: Decomposição da variância (fluxos financeiros em relação ao câmbio) - (\%)

\begin{tabular}{c|l|l|l|l|l|l}
\hline \hline Período & DACB & ARF & DER & IEC & IED & OIE \\
\hline 1 & 0.000000 & 0.000000 & 0.000000 & 0.000000 & 0.000000 & 0.000000 \\
\hline 4 & 1.588198 & 1.506716 & 2.351551 & 3.280876 & 0.982994 & 0.386894 \\
\hline 10 & 2.444084 & 2.540638 & 3.099016 & 3.571457 & 1.770257 & 0.788656 \\
\hline \hline
\end{tabular}

Fonte: Saída do Eviews 4.1.

Na tabela 7 é apresentado o quanto a taxa de câmbio explica a variância das variáveis financeiras do modelo, através da decomposição da variância. Destaca-se neste contexto a importância do câmbio na variância, sobretudo, dos fluxos financeiros de mais curto prazo, representados pela sub-conta IEC com 3,57\% e em suas desagregações, DACB com 2,44\% e ARF com 2,54\%.

De maneira geral, os resultados encontrados pela aplicação do modelo VAR indicam que elementos provenientes do mercado financeiro podem explicar boa parte da apreciação cambial ocorrida na economia brasileira no período analisado. Assim, é justificada a interpretação de que fatores conjunturais, sobretudo os ciclos de liquidez internacional, que são importantes determinantes dos influxos de capitais nas economias emergentes, são importantes na análise da apreciação cambial da última década. No entanto, existem outras variáveis relevantes na explicação do comportamento da taxa de câmbio não captadas no modelo, uma vez que este procurou focar na análise financeira. 


\section{Considerações finais}

Este trabalho procurou analisar as relações e influências existentes entre o comportamento da taxa de câmbio brasileira e os influxos de capitais no país, principalmente a tendência de apreciação observada na última década. Apesar de haver diversas variáveis que são capazes de explicar os movimentos da taxa de câmbio, este trabalho parte da ideia de que os fluxos financeiros possuem um peso significativo nesta análise, podendo influenciar tanto movimentos de apreciação quanto de depreciação.

O referencial teórico analisado, que trata desde os problemas decorrentes da liberalização financeira, até ao perfil dos fluxos que ingressam no Brasil, apontam que a livre modalidade de capitais tende a ser prejudicial à dinâmica econômica, sobretudo, de economias emergentes como a brasileira. Por existirem assimetrias financeiras e monetárias no sistema financeiro e monetário internacional, que se expressam diretamente na hierarquia de moedas, as economias emergentes, por possuírem moedas não conversíveis precisam oferecer um diferencial de juros em relação às economias detentoras de moedas conversíveis, para atraírem os investidores externos. A taxa de juros mais alta, além de já representar impedimentos à dinâmica econômica, principalmente no tocante ao estímulo aos investimentos produtivos, carrega outro problema a economias emergentes por cumprirem a função de atraírem fluxos predominantemente especulativos, que se guiam na busca de ganhos extraordinários em curto período de tempo.

Assim, ao se analisar o perfil dos fluxos financeiros transacionados na economia brasileira de 2003 a 2013, através da análise da conta financeira do balanço de pagamentos, vê-se que há intensa volatilidade no comportamento dos fluxos, sendo as sub-contas investimento em carteira e outros investimentos as mais representativas desta instabilidade, justamente as que registram os fluxos de caráter mais especulativo.

Neste sentido, a abordagem econométrica contribui ao buscar mostrar se o ingresso dos fluxos financeiros exerce influência no comportamento da taxa de câmbio. Os resultados encontrados apontam que, na maior parte do período, a taxa de câmbio responde negativamente aos impulsos dos fluxos financeiros, o que indica que, por exemplo, um ingresso maior de investimento direto, investimento em carteira, derivativos e outros investimentos tendem a apreciar a taxa de câmbio. Ademais, ao observar os impulsos das subcontas de ingresso de ações de companhias brasileiras e ações de renda fixa, que representam a desagregação em terceiro nível da sub-conta IEC, vê-se o quanto a taxa de câmbio tende a se apreciar, o que indica, conforme o referencial teórico analisado, que os fluxos financeiros de mais curto prazo tendem a exercer forte influência do comportamento da taxa de câmbio.

Logo, apesar de as variáveis financeiras não explicarem por si só o comportamento do câmbio, o modelo VAR apontou que estes fluxos são significativos nesta explicação, o que justifica a interpretação de que fatores conjunturais, sobretudo os ciclos de liquidez internacional, que são importantes determinantes dos influxos de capitais nas economias emergentes, são importantes na análise da apreciação cambial da última década. Ademais, entende-se que deve ser dada atenção ao comportamento destas variáveis por parte dos policy makers, sobretudo no tocante à livre mobilização destes, no sentido de se buscar a melhor combinação dos fluxos a fim de se evitar a especulação e buscar fluxos mais produtivos e que auxiliem na redução da vulnerabilidade externa do país. 


\section{REFERÊNCIAS BIBLIOGRÁFICAS}

BANCO CENTRAL DO BRASIL. Economia e Finanças. Séries Temporais. Disponível em: <http://www4.bcb.gov.br/?SERIESTEMP>. Acesso em junho de 2014.

BANCO CENTRAL DO BRASIL. Notas explicativas ao Balanço de Pagamentos compilado de acordo com as normasestabelecidas na quinta edição do Manual de Balanço de Pagamentos do FMI. Disponível em: $<$ http://www.bcb.gov.br/ftp/infecon/NotasExplBPM5.pdf $>$. Acesso em junho de 2014.

BANCO CENTRAL DO BRASIL. Notas técnicas do Banco Central do Brasil. Brasília, 2001.

BMF\&BOVESPA. O que são derivativos. Disponível em: $<$ http://www.bmfbovespa.com.br/pt-br/educacional/iniciantes/mercados-de-derivativos/o-quesao-derivativos/o-que-sao-derivativos.aspx?idioma=pt-br> Acesso em junho de 2014.

BRAGA, M. B.; PAULANI, L. M. A nova contabilidade social: uma introdução à Macroeconomia. $3^{\text {a }}$ ed. Ver. E atualizada. São Paulo: Saraiva, 2007.

BUENO, R. de L. da. S. Econometria de Séries Temporais. CENGAGE Learning Edições Ltda, São Paulo, 2008.

CARNEIRO, R. Globalização financeira e inserção periférica. In: Economia e Sociedade, Campinas: UNICAMP/ Instituto de Economia, (13): p. 57-92, Dezembro, 1999.

CARVALHO, F. C.; SICSÚ, J. Controvérsias recentes sobre controles de capitais. In: SICSÚ, J. ; FERRARI FILHO, F. Câmbio e controle de capitais: avaliando a eficiência de modelos macroeconômicos. Rio de Janeiro: Elsevier, 2006.

CEPAL (Comissão Econômica para a América Latina e o Caribe). Globalização e Desenvolvimento. Publicação das Nações Unidas. Brasília, Brasil, maio, 2002.

DAMASCENO, A. O. Integração financeira internacional e crescimento econômico: uma crítica à abordagem convencional. In: Economia e Sociedade, Campinas: UNICAMP/ Instituto de Economia, vol.16, nº 2 (30), p. 171 - 198, agosto, 2007.

GUJARATI, D. Econometria Básica. São Paulo: Makron Books. Quarta Edição, 2006.

INSTITUTO DE PESQUISA ECONÔMICA APLICADA (IPEA). IPEA-DATA. Disponível em: <http://www.ipeadata.gov.br $>$. Acesso em junho de 2014..

KEYNES, J. M. The General Theory of Employment Interest and Money.New York: harcourt, Brace\&Co, 1936. Trad. Bras. A Teoria Geral do Emprego, do Juro e da Moeda. São Paulo: Nova Cultural, 1985.

MINSKY, H. P. Stabilizing an unstable economy.Yale University Press., 1986. Trad.Bras.Estabilizando uma economia instável. São Paulo: Novo Século Editora, 2009. 
MUNHOZ, V. C. V. Vulnerabilidade externa e controle de capitais no Brasil: uma análise das inter-relações entre câmbio, fluxos de capitais, IOF, juros e risco-país. In: Nova Economia, vol. 23, nº 2, Belo Horizonte, mai-ago de 2013.

MUNHOZ, V. C. V., CORRÊA, V. P. Volatilidade dos fluxos financeiros no Brasil: uma análise empírica por meio do modelo ARCH (modelo auto-regressivo com heterocedasticidade condicional). In: Análise Econômica, ano 27, n⿳⺈ 52, p. 201-232, Porto Alegre, setembro de 2009.

MUNHOZ, V. C. V., LIBÂNIO, G. Volatilidade dos fluxos financeiros e fuga de capitais: uma análise exploratória da vulnerabilidade externa no Brasil. In: Texto para discussão, $\mathrm{n}^{\circ}$ 371, UFMG - Cedeplar, novembro de 2009.

MUNHOZ, V. C. V., VERÍSSIMO, M. P. Fluxos de capitais versus exportações de commodities: efeitos sobre a taxa de câmbio real brasileira no período 2000-2013. In: Anais do $4^{\circ}{ }^{\circ}$ Encontro Nacional de Economia, dezembro de 2013.

PLIHON, D. A ascensão das finanças especulativas. In: Economia e Sociedade, Campinas: UNICAMP/ Instituto de Economia, vol. 5, dezembro, 1995.

PRATES, D.M. A abertura financeira dos países periféricos e os determinantes dos fluxos de capitais. In: Revista de Economia Política, vol.19, nº1, 1999.

ROSSI, P. Padrões de integração financeira e a volatilidade das taxas de câmbio e juros em países periféricos. In: OIKOS, vol. 9, nº 1, Rio de Janeiro, 2010. 